\title{
Effects of Weight Loss with and without Exercise on Regional Body Fat Distribution in Postmenopausal Women
}

\author{
Monica C. Serra Jacob B. Blumenthal Odessa R. Addison Ann J. Miller \\ Andrew P. Goldberg Alice S. Ryan \\ Baltimore VA Medical Center and University of Maryland School of Medicine, Baltimore, MD, USA
}

\section{Keywords}

Weight loss · Aerobic exercise - Postmenopausal women ·

Body fat distribution

\begin{abstract}
Background/Aims: The purpose was to determine whether lifestyle interventions have different effects on regional fat in women with normal glucose tolerance vs. impaired glucose tolerance (NGT vs. IGT). Methods: Changes in glucose metabolism (2-h oral glucose-tolerance tests), android to gynoid fat mass ratio (dual energy $X$-ray absorptiometry [DXA]), visceral to subcutaneous abdominal fat area ratio (CT), and abdominal to gluteal subcutaneous fat cell weight (FCW; adipose tissue biopsies) were determined in 60 overweight postmenopausal women (45-80 years) following 6 months of weight loss alone (WL; $n=28)$ or with aerobic exercise (AEX + WL; $n=32$ ). Results: The interventions led to $\sim 8 \%$ decrease in weight, but only the $A E X+W L$ group improved fitness ( $\uparrow 11 \%$ in $\mathrm{VO}_{2}$ max) and reduced the android-to-gynoid fat mass ratio $(\downarrow 5 \%$; $p<0.05)$. Both NGT and IGT groups reduced visceral and subcutaneous abdominal fat areas and abdominal and gluteal FCWs, which related to improvements in homeostatic model assessment $(r=0.34-0.42)$ and 2 -h glucose $(r=0.34-0.35)$, respectively $(p<0.05)$. The decline in FCW was $2 \times$ greater in women with IGT following WL $(p<0.05)$. The ratios of abdominal-to-gluteal FCW did not
\end{abstract}

\section{KARGER}

Published by S. Karger AG, Basel

E-Mail karger@karger.com

www.karger.com/anm change following either intervention. Conclusions: The mechanisms by which WL with and without exercise impact regional fat loss should be explored as reductions in abdominal fat area and subcutaneous FCW appear to influence glucose metabolism.

$$
\begin{array}{r}
\text { This is a work of the U.S. Government and is not subject to } \\
\text { copyright protection in the United States. Foreign copyrights may apply. } \\
\text { Published by S. Karger AG, Basel }
\end{array}
$$

\section{Introduction}

Central (android) obesity is associated with an increased risk for metabolic dysfunction compared to gluteal/femoral (gynoid) obesity [1]. Metabolically unhealthy men and women with impaired glucose tolerance (IGT) tend to have a greater body mass index (BMI) and waistto-hip ratio (WHR) than normal glucose-tolerant (NGT) adults [2]. Obese persons with larger abdominal fat areas compared to gluteal fat cells have higher fasting insulin and glucose levels $[3,4]$, indicating that the accumulation of fat in the android region places obese individuals at higher metabolic risk. Fat located within the android region may be located both inside (visceral) and outside (subcutaneous) of the abdominal cavity. Insulin sensitivity by a hyperinsulinemic-euglycemic clamp is related to both subcutaneous and visceral abdominal fat [5], but
Monica C. Serra

Baltimore VA Medical Center and University of Maryland School of Medicine 10 N. Greene St., GRECC (BT/18/GR)

Baltimore, MD 21201 (USA)

E-Mail monica.serra@va.gov 
there is evidence that subcutaneous abdominal fat retains significance after adjusting for visceral fat [6], suggesting that the location of fat within the android region also affects metabolic risk. Understanding the interrelationships among regional fat distribution, obesity, and risk for type 2 diabetes mellitus (T2DM) is especially relevant in obese postmenopausal women, since menopause is associated with a shift of fat deposition from gynoid and toward android adiposity and this shift increases risk for T2DM [7].

Weight loss (WL)-induced reductions in abdominal fat cell size $[8,9]$ are associated with declines in upper body fat mass [10] and improvements in insulin sensitivity by a hyperinsulinemic-euglycemic clamp [11]. However, we showed that the addition of aerobic exercise to $\mathrm{WL}$ results in greater reductions in 2-h insulin than WL alone [12]. Moreover, the addition of exercise to WL is associated with the preferential reduction in subcutaneous abdominal fat cell weight (FCW) compared to WL alone, but WL both with and without aerobic exercise reduces gluteal fat cell size equivalently [13]. Thus, literature indicates that the ratio of android to gynoid fat cell size increases following WL alone, but does not change with the addition of exercise [13]. Conversely, despite evidence that visceral abdominal fat change is inversely related to increases in $\mathrm{VO}_{2} \mathrm{max}$, preferential loss of subcutaneous, visceral, or the ratio of subcutaneous to visceral abdominal fat is not observed when comparing the effects of WL with and without exercise [14], and reductions in visceral and subcutaneous abdominal fat following both interventions appear to result in glucose metabolic improvements (i.e., improvements in fasting plasma glucose and insulin, glucose tolerance or insulin sensitivity) $[12,15,16]$.

The degree of glucose metabolic improvements during WL with and without aerobic exercise may vary depending upon baseline glucose-tolerance status. Improvements in glucose metabolism are greater in adults with T2DM and IGT compared to those with NGT following either WL alone $[17,18]$ or when aerobic exercise is combined with WL $[12,19,20]$. However, how baseline glucose tolerance affects the changes in the distribution of fat, which may influence glucose metabolism, following these lifestyle interventions has not been compared and studied in postmenopausal women. Therefore, this study examines the hypothesis that in overweight and obese postmenopausal women with IGT, WL alone, but more so with the addition of aerobic exercise, will result in greater reductions in upper than lower body fat (i.e., greater reductions in WHR, android-to-gynoid FM ratio, and abdominal-to-gluteal FCW ratio), as well as greater reductions in visceral than subcutaneous abdominal fat area, than in women with NGT. Further, we explore whether greater reductions in the fat distribution ratios are associated with greater improvements in glucose metabolism.

\section{Materials and Methods}

\section{Study Overview}

Sedentary ( $<20 \mathrm{~min}$ of aerobic exercise $2 \times /$ week), overweight, and obese, postmenopausal (age 45-80 years) women were recruited for this study from the Baltimore area. A medical history, physical examination, resting 12-lead electrocardiogram, and fasting blood profile were obtained to exclude those with unstable medical conditions. Subjects with evidence of unstable hypertension and hypertriglyceridemia, heart disease, cancer, liver, renal or hematological disease, orthopedic limitations, or medical conditions deemed to impact participation were excluded. All women signed the University of Maryland Institutional Review Board approved informed consent forms.

Participants were part of a larger clinical trial [12] examining the effects of WL alone and WL with aerobic exercise (AEX + WL) on insulin sensitivity and skeletal muscle metabolism $(n=96)$. Women without diabetes who completed dual energy X-ray absorptiometry (DXA) and CT scans, oral glucose-tolerance tests (OGTT), and adipose tissue biopsies pre- and post-intervention $(n=60)$ were involved in the current analysis. Some of the results have been previously published [12], but changes in the ratios of regional body fat and FCW are unique to this manuscript. $\mathrm{VO}_{2}$ max was measured by indirect calorimetry during a graded exercise test on a treadmill as previously described [12]. Subjects met with a registered dietitian (RD) weekly for approximately 4-6 weeks to learn a heart healthy diet (i.e., $<30 \%$ of diet as total fat, $<10 \%$ of diet as saturated fat, $<2,400 \mathrm{mg}$ sodium, with more fruits, vegetables, and complex carbohydrates) prior to completing baseline testing in order to minimize the effects of diet composition on metabolism [21]. Then, all subjects met weekly for 6 months with the RD to learn techniques for consuming a hypocaloric (250-350 kcal/day deficit), hearthealthy diet designed to promote $\sim 1.0-1.5 \mathrm{~kg}$ WL per month. In addition, women in the AEX + WL group exercised 3 days per week for 6 months using treadmills and elliptical trainers. Training programs were gradually progressed in duration and intensity until the participant was able to exercise at $>85 \%$ heart rate reserved for $45 \mathrm{~min}$. The average adherence to exercise and WL classes was approximately $86 \%$. Following the interventions, all subjects were weight stabilized $( \pm 2 \%)$ for 10 days prior to post-testing.

\section{Body Composition}

Height and body weight were measured using a stadiometer and electric scale to calculate BMI (weight $[\mathrm{kg}] /$ height $\left[\mathrm{m}^{2}\right]$ ). A total body DXA scan (DPX-IQ; Lunar Corp., Madison, WI, USA) was performed to determine total body fat-free mass (lean tissue mass + bone mineral content), fat mass, and \% body fat, as well as regional fat mass in the android and gynoid regions. Standard definitions of android and gynoid regions, as defined by the Lunar software, were used. Briefly, the android region is the area around the waist between the mid-point of the lumbar spine and the top of the pelvis and the gynoid region is between the head of the femur and mid-thigh [22]. CT scans were performed with a PQ 6000 scanner (Marconi Medical Systems, Cleveland, OH, USA) to 
quantify subcutaneous and visceral abdominal fat areas using a single 5-mm scan taken at the L4-L5 region, while the subject was in a supine position, with arms stretched overhead. CT data are expressed as cross-sectional area of tissue $\left(\mathrm{cm}^{2}\right)$, where adipose tissue is considered -190 to $-30 \mathrm{HU}$ [12].

\section{Glucose Metabolism}

Blood was collected after $12 \mathrm{~h}$ of fasting and at $30 \mathrm{~min}$ intervals for $2 \mathrm{~h}$ after subjects ingested $75 \mathrm{~g}$ of glucose during an OGTT to determine the glucose-tolerance status [23] and total glucose and insulin area under the curve (by trapezoidal method [24]). Plasma glucose concentrations were measured using the glucose oxidase method (2300 STAT Plus; YSI, Yellow Springs, OH, USA). Immunoreactive insulin was measured by radioimmunoassay (Linco Research Inc., St. Charles, MO, USA). Intra- and inter-assay coefficients of the variation of pooled control sera average 5 and $9 \%$, respectively. Baseline values were used to estimate insulin resistance via the homeostatic model assessment (HOMA-IR). HOMA-IR was calculated as (fasting insulin $[\mu \mathrm{U} / \mathrm{mL}] \times$ fasting glucose $[\mathrm{mmol} / \mathrm{L}]) / 22.5)[25]$. Post-intervention OGTTs were performed $36-48 \mathrm{~h}$ after the last bout of exercise. Glucose metabolic improvements were considered improvements in any of the following: fasting plasma glucose and insulin, HOMA-IR, and glucose-tolerance or insulin response during the OGTT.

\section{Fat Cell Weight}

Fat aspirations from both the abdominal (ABD) and gluteal (GLT) regions were performed. Participants consumed 2 days of a metabolically stable diet prior to the fat aspiration. After subjects underwent a 12-h overnight fast, subcutaneous adipose tissue was aspirated under local anesthesia ( $0.5 \%$ xylocaine) from both the $\mathrm{ABD}$ and GLT regions using a $10 \mathrm{~mm}$ mini-cannula, and fat cells were isolated by collagenase digestion $(1 \mathrm{mg} / \mathrm{mL})$ and FCW s of at least 300 cells per site, with a diameter between 25 and $250 \mu \mathrm{m}$, were calculated $(\mathrm{FCW}=$ $0.915 / 10^{6} \times \pi / 6 d^{3}$, where $d$ is the diameter in microns) as previously described $[26,27]$. In the AEX + WL group, the post biopsies were performed within $24-36 \mathrm{~h}$ of the last exercise session.

\section{Statistics}

At baseline, between-group comparisons of IGT vs. NGT were performed using independent Student $t$ tests. A $\chi^{2}$ test was used to determine whether the prevalence of African American and Caucasian women differed between groups. Three factorial ANOVAs (time*intervention*IGT status) with Bonferroni post hoc tests were used to determine the differences in the effect of the intervention (WL vs. AEX + WL) on fat distribution variables by glucosetolerance status (IGT vs. NGT). Pearson and partial correlations were used to assess relationships between key variables. Statistical significance was set at a 2 -tailed $p<0.05$. Data were analyzed using SPSS (PAWS Statistics, version 18, Chicago, IL, USA). Results are expressed as mean \pm SEM.

\section{Results}

\section{Baseline Comparisons of Data by Glucose-Tolerance Status}

Women with IGT were of comparable body weight, BMI, and \% total body fat as those with NGT, but were
Table 1. Baseline subject characteristics stratified by glucose tolerance status

\begin{tabular}{lcc}
\hline & NGT $(n=35)$ & IGT $(n=25)$ \\
\hline Race (\% Caucasian) & 69 & 56 \\
Age, years & $58 \pm 1$ & $63 \pm 1^{* *}$ \\
Weight, kg & $86 \pm 2$ & $91 \pm 3$ \\
BMI, kg/m & $32 \pm 1$ & $35 \pm 1$ \\
Waist circumference, cm & $94 \pm 2$ & $103 \pm 3^{* *}$ \\
Hip circumference, cm & $117 \pm 2$ & $122 \pm 3$ \\
Waist to hip ratio & $0.80 \pm 0.01$ & $0.85 \pm 0.01^{* *}$ \\
Body fat, \% & $47 \pm 1$ & $49 \pm 1$ \\
Total body fat mass, kg & $41 \pm 2$ & $45 \pm 2$ \\
Total body fat-free mass, kg & $46 \pm 1$ & $47 \pm 1$ \\
Android fat mass, kg & $3.4 \pm 0.2$ & $4.0 \pm 0.2^{*}$ \\
Gynoid fat mass, kg & $7.6 \pm 0.3$ & $7.8 \pm 0.4$ \\
Android/gynoid fat mass & $0.44 \pm 0.01$ & $0.49 \pm 0.01^{* *}$ \\
Visceral abdominal fat area, cm ${ }^{2}$ & $137 \pm 11$ & $175 \pm 16$ \\
Subcutaneous abdominal fat area, cm ${ }^{2}$ & $446 \pm 28$ & $426 \pm 31$ \\
Visceral/subcutaneous abdominal fat ratio & $0.31 \pm 0.03$ & $0.44 \pm 0.05^{* *}$ \\
Abdominal FCW, $\mu$ g triglyceride/cell & $0.56 \pm 0.02$ & $0.61 \pm 0.03^{* *}$ \\
Gluteal FCW, $\mu \mathrm{g}$ triglyceride/cell & $0.62 \pm 0.02$ & $0.66 \pm 0.02$ \\
Abdominal/gluteal FCW & $0.91 \pm 0.02$ & $0.95 \pm 0.03$ \\
Absolute $\mathrm{VO}_{2}$ max, L/min & $1.7 \pm 0.1$ & $1.5 \pm 0.1$ \\
Relative $\mathrm{VO}_{2}$ max, mL/kg/min & $20.3 \pm 0.8$ & $16.7 \pm 0.9^{* *}$ \\
\hline
\end{tabular}

Significantly different from NGT. ${ }^{*} p<0.05,{ }^{* *} p<0.01$.

Table 2. Glucose and insulin responses to an OGTT in subjects classified as having NGT vs. IGT

\begin{tabular}{lcc}
\hline & NGT & IGT \\
\hline Fasting glucose, mmol/L & $5.3 \pm 0.1$ & $5.5 \pm 0.1$ \\
Fasting insulin, pmol/L & $74 \pm 5$ & $110 \pm 10^{* *}$ \\
HOMA-IR & $2.9 \pm 0.2$ & $4.5 \pm 0.5^{* *}$ \\
2-H glucose, mmol/L & $5.9 \pm 0.2$ & $9.0 \pm 0.2^{* *}$ \\
2-H insulin, $\mathrm{pmol} / \mathrm{L}$ & $408 \pm 51$ & $903 \pm 134^{* *}$ \\
Glucose AUC, $\mathrm{mmol} / \mathrm{L} / 120 \mathrm{~min}$ & $824 \pm 20$ & $1,052 \pm 24^{* *}$ \\
Insulin AUC, $\mathrm{pmol} / \mathrm{L} / 120 \mathrm{~min}$ & $54,305 \pm 3,938$ & $73,648 \pm 10,006^{*}$ \\
\end{tabular}

Significantly different from NGT. ${ }^{* *} p<0.05,{ }^{* *} p<0.01$.

older and had an $18 \%$ lower relative $\mathrm{VO}_{2} \max (p<0.01$; Table 1). Race distribution did not differ by the glucosetolerance status. As anticipated, HOMA-IR, 2-h glucose and insulin, and glucose and insulin area under the curve (AUC) were higher in women with IGT $(p<0.05$; Table 2). Women with IGT had higher waist circumference, android fat mass, and visceral fat area, which resulted in a higher waist-to-hip, android-to-gynoid fat mass, and visceral-to-subcutaneous abdominal fat ratios $(p<0.05)$. Although abdominal FCW also was 
Table 3. Relationships of baseline body fat distribution ratios to baseline and changes in glucose tolerance

\begin{tabular}{|c|c|c|c|c|}
\hline Pearson coefficients & $\begin{array}{l}\text { Baseline waist/ } \\
\text { hip circumference }\end{array}$ & $\begin{array}{l}\text { Baseline android/ } \\
\text { gynoid fat mass }\end{array}$ & $\begin{array}{l}\text { Baseline abdominal/ } \\
\text { gluteal FCW }\end{array}$ & $\begin{array}{l}\text { Baseline visceral/ } \\
\text { subcutaneous fat areas }\end{array}$ \\
\hline \multicolumn{5}{|c|}{ Fasting glucose, $\mathrm{mmol} / \mathrm{L}$} \\
\hline Baseline & 0.04 & $0.28^{*}$ & 0.10 & $0.48^{* *}$ \\
\hline Change & -0.09 & -0.20 & -0.17 & $-0.38^{*}$ \\
\hline \multicolumn{5}{|c|}{ Fasting insulin, pmol/L } \\
\hline Baseline & $0.49^{* *}$ & $0.32^{*}$ & $0.30^{*}$ & $0.46^{* *}$ \\
\hline Change & $-0.35^{* *}$ & $-0.27^{*}$ & $-0.24^{*}$ & $-0.32^{*}$ \\
\hline \multicolumn{5}{|l|}{ HOMA-IR } \\
\hline Baseline & $0.45^{* *}$ & $0.34^{*}$ & $0.29^{*}$ & $0.52^{* *}$ \\
\hline Change & $-0.34^{*}$ & $-0.31^{*}$ & $-0.25^{*}$ & $-0.45^{* *}$ \\
\hline \multicolumn{5}{|l|}{ 2-H glucose, $\mathrm{mmol} / \mathrm{L}$} \\
\hline Baseline & 0.25 & $0.28^{*}$ & -0.08 & $0.40^{* *}$ \\
\hline Change & -0.12 & -0.22 & -0.08 & $-0.39^{* *}$ \\
\hline \multicolumn{5}{|l|}{ 2-H insulin, $\mathrm{pmol} / \mathrm{L}$} \\
\hline Baseline & $0.33^{*}$ & $0.37^{* *}$ & 0.18 & 0.20 \\
\hline Change & -0.13 & $-0.37^{*}$ & -0.20 & -0.36 \\
\hline \multicolumn{5}{|c|}{ Glucose AUC, $\mathrm{mmol} / \mathrm{L} / 120 \mathrm{~min}$} \\
\hline Baseline & 0.15 & $0.28^{*}$ & $0.34^{* *}$ & $0.39^{*}$ \\
\hline Change & 0.01 & -0.15 & 0.07 & $-0.32^{*}$ \\
\hline \multicolumn{5}{|c|}{ Insulin AUC, pmol/L/120 min } \\
\hline Baseline & $0.31^{*}$ & $0.36^{* *}$ & 0.20 & 0.14 \\
\hline Change & -0.07 & -0.22 & 0.09 & 0.14 \\
\hline
\end{tabular}

Controlled for age and $\mathrm{VO}_{2}$ max. $* p<0.05 ; * * p<0.01$.

higher in women with IGT $(p<0.05)$, the ratio of abdominal to gluteal FCW was similar in women with IGT vs. NGT.

After controlling for baseline age and $\mathrm{VO}_{2} \max$, a greater ratio of upper to lower body fat was associated with worse glucose metabolic profiles (Table 3 ). These relationships appear to be driven by upper body fat, as upper body fat was a stronger predictor of HOMA-IR and 2-h glucose than the lower body equivalent (HOMA-IR: waist vs. hip circumference: $r=0.58$ $[p<0.01]$ vs. $r=0.38[p<0.01]$; android vs. gynoid fat mass: $r=0.48[p<0.01]$ vs. $r=0.35[p<0.01]$, and abdominal vs. gluteal FCW: $r=0.38[p<0.05]$ vs. $r=0.24$ $[p=\mathrm{ns}] ;$ 2-h glucose: waist vs. hip circumference: $r=$ $0.36[p<0.01]$ vs. $r=0.25[p=\mathrm{ns}]$; android vs. gynoid fat mass: $r=0.37[p<0.05]$ vs. $r=0.31[p=\mathrm{ns}]$, and abdominal vs. gluteal FCW: $r=0.30[p<0.05]$ vs. $r=$ $0.24[p=n s])$. Further, greater visceral-to-subcutaneous abdominal fat area ratio was associated with worse glucose metabolic profiles (Table 3 ), with visceral fat area being a stronger predictor of glucose intolerance than subcutaneous abdominal fat area (HOMA-IR: $r=0.68$ [ $p<0.01]$ vs. $r=0.38$ [ $p<0.01]$; 2-h glucose: $r=0.32$ $[p<0.01]$ vs. $r=0.04[p=\mathrm{ns}])$.

WL, Exercise, and Body Fat Distribution
Effects of WL with and without Exercise on Regional

Fat Distribution and FCW (Table 4)

Similar to our prior report [12], weight change was comparable across groups ( $~ 8 \%)$, but only those in the AEX + WL groups improved $\mathrm{VO}_{2} \max$ (WL vs. AEX + WL: -3 vs. $+11 \% ; p<0.01)$ and maintained FFM $(-4$ vs. $-1 \%$; $p<0.05)$, and these improvements were similar between NGT and IGT groups within each intervention. Although there were no time*intervention*IGT status interactions for changes in glucose metabolism, there was a significant group*time effect, which showed that women with IGT had greater reductions in fasting insulin (IGT vs. NGT: -26 vs. $-16 \%$ ), 2-h glucose ( -18 vs. $+5 \%)$, insulin AUC ( -44 vs. $-16 \%)$, glucose AUC (-10vs. $-2 \%)$, and HOMA-IR (-32 vs. $-21 \%)$ than women with NGT, independent of intervention $(p<$ 0.05 ; data available in online suppl. Table 1, see www.karger.com/doi/10.1159/000475766).

A decline in waist and hip circumference, android and gynoid fat mass, abdominal and gluteal FCW, and visceral and subcutaneous abdominal fat area was observed $(p<0.05)$ in each group following both interventions. The changes in ABD and GLT FCW were around twofold greater in women with IGT who underwent WL alone compared to all other groups ( $p<0.01$; Fig. 1$)$. 


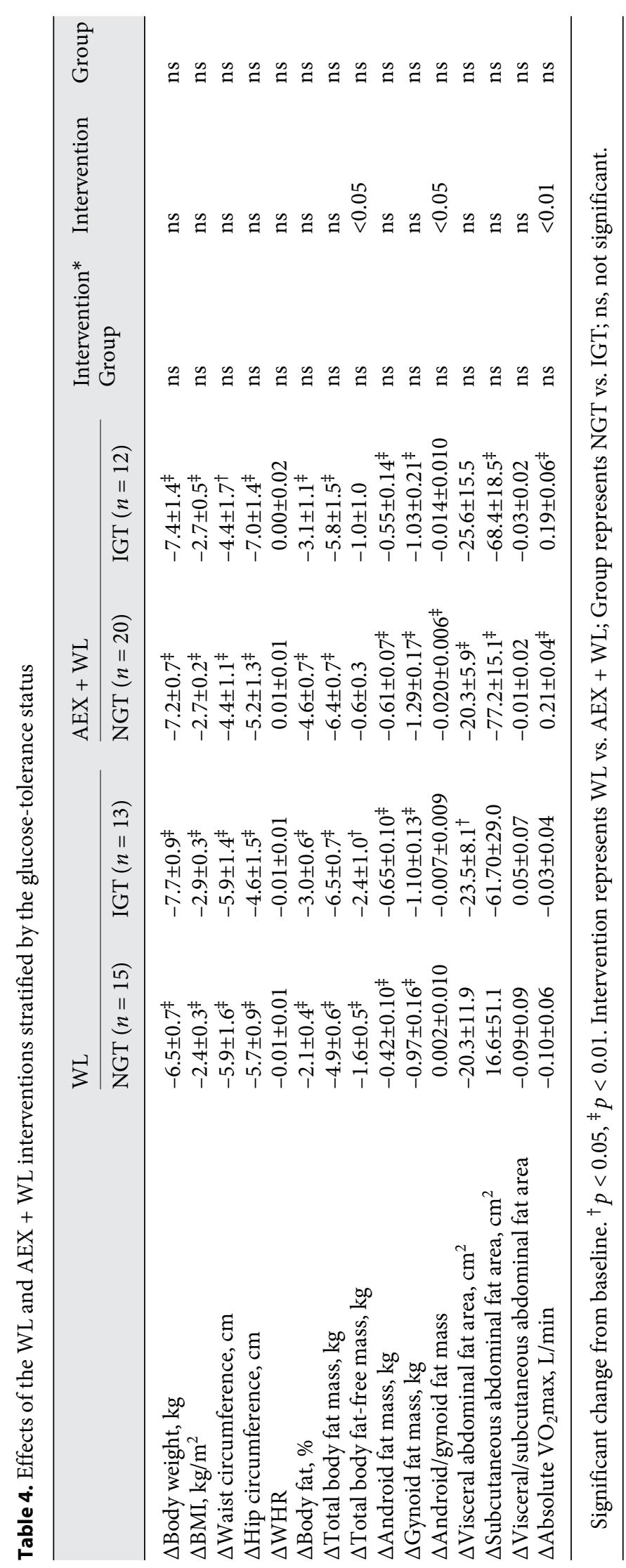

This remained true even after adjusting for changes in body fat. The declines in upper and lower body circumference and FCW and abdominal fat areas were similar by region, as there were no changes in the waist-to-hip circumference, abdominal-to-gluteal FCW, or visceralto-subcutaneous abdominal fat area ratios in either IGT or NGT groups. However, the decline in android-to-gynoid fat mass ratio was significant in women following AEX + WL (Fig. 2a), but not WL alone (WL vs. AEX + WL: -1 vs. $-5 \% ; p<0.05$; Fig. $2 \mathrm{~b})$, regardless of the IGT status.

\section{Relationships of Changes in Regional Fat Distribution and FCW to Glucose Metabolism after the Interventions}

Glucose metabolic improvements (i.e., fasting and 2-h glucose and insulin and HOMA-IR) negatively related to lower baseline android-to-gynoid fat mass and visceralto-subcutaneous abdominal fat area ratios, but not WHR or ABD-to-GLT FCW ratio (Table 3). However, the changes in these glucose- and insulin-associated variables did not correlate with changes in waist or hip circumference, WHR, android or gynoid fat mass, or the ratio of android to gynoid fat mass in the total group. After adjusting for changes in body fat, reductions in 2-h glucose and glucose AUC were associated with declines in ABD FCW (2-h glucose: $r=0.35$; Fig. 3a; glucose AUC: $r=$ 0.28 ) and GLT FCW (2-h glucose: $r=0.34$; Fig. 3b; glucose AUC: $r=0.31 ; p<0.05)$, but not the ratio of ABD to GLT FCW. Reductions in fasting glucose and HOMA-IR were associated with declines in visceral (fasting glucose: $r=0.31$; HOMA-IR: $r=0.42$ ) and subcutaneous (fasting glucose: $r=0.36$; HOMA-IR: $r=0.34$ ) abdominal fat areas $(p<0.05)$ but not the ratio of visceral to subcutaneous abdominal fat area.

\section{Discussion}

Despite observing a greater decline in android-togynoid fat mass ratio in women who underwent aerobic exercise in addition to WL, we did not find that a greater change in upper vs. lower body fat or visceral to subcutaneous fat area is a mediator of glucose metabolism following WL with and without aerobic exercise. Rather, we find that greater reductions in FCW and abdominal fat area (absolute changes, not the ratios) are associated with improvements in glucose tolerance following WL and AEX $+\mathrm{WL}$. The relationship is similar for the abdominal and gluteal region and the visceral and subcutaneous ab- 


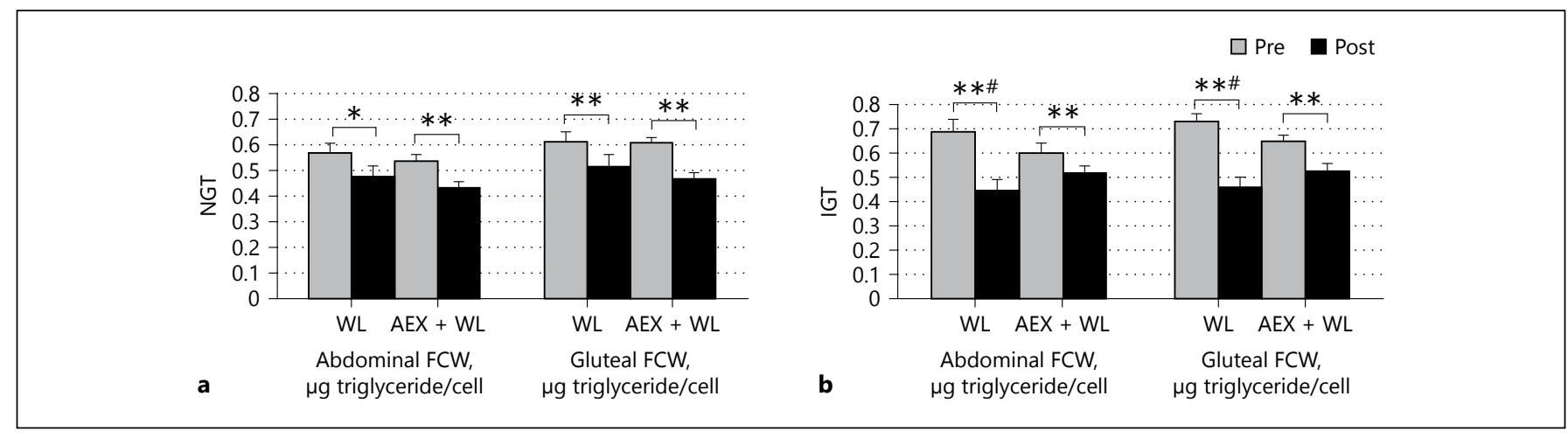

Fig. 1. Changes in fat cell weight following WL with (AEX + WL) and without aerobic exercise (WL) in those with normal (NGT; a) and impaired (IGT; b) glucose tolerance. ${ }^{*} p<0.05,{ }^{* *} p<0.01$ : significant change from pre. ${ }^{\#} p<0.05$ : the change is significantly different from all other groups (IGT following AEX $+\mathrm{WL}$ and NGT following WL and AEX + WL).

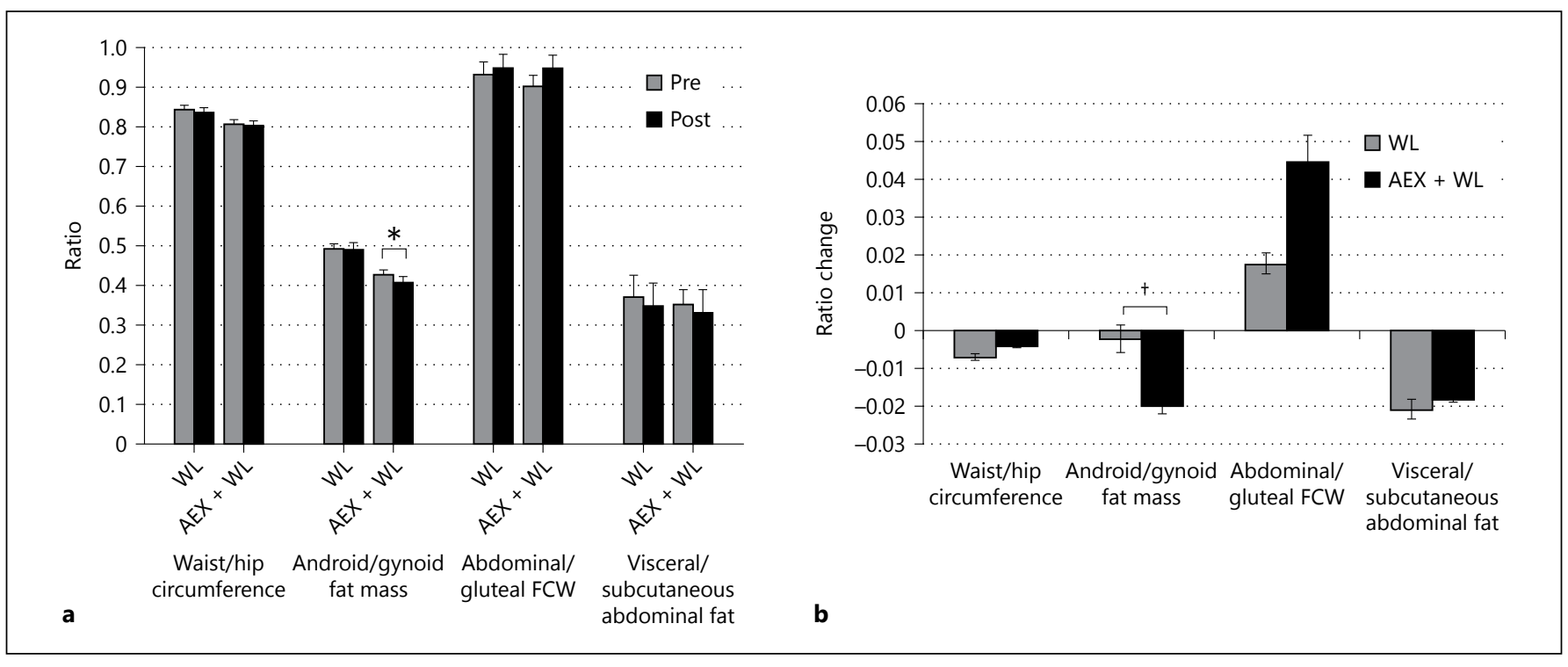

Fig. 2. Bar graphs representing the changes in the ratios of body fat distribution (raw data, a; change data, b). Normal and impaired glucose-tolerance groups were combined as no "glucose-tolerance status" group differences were observed. ${ }^{*} p<0.05$ : significantly different than pre. ${ }^{\dagger} p<0.05$ : significantly different than WL.

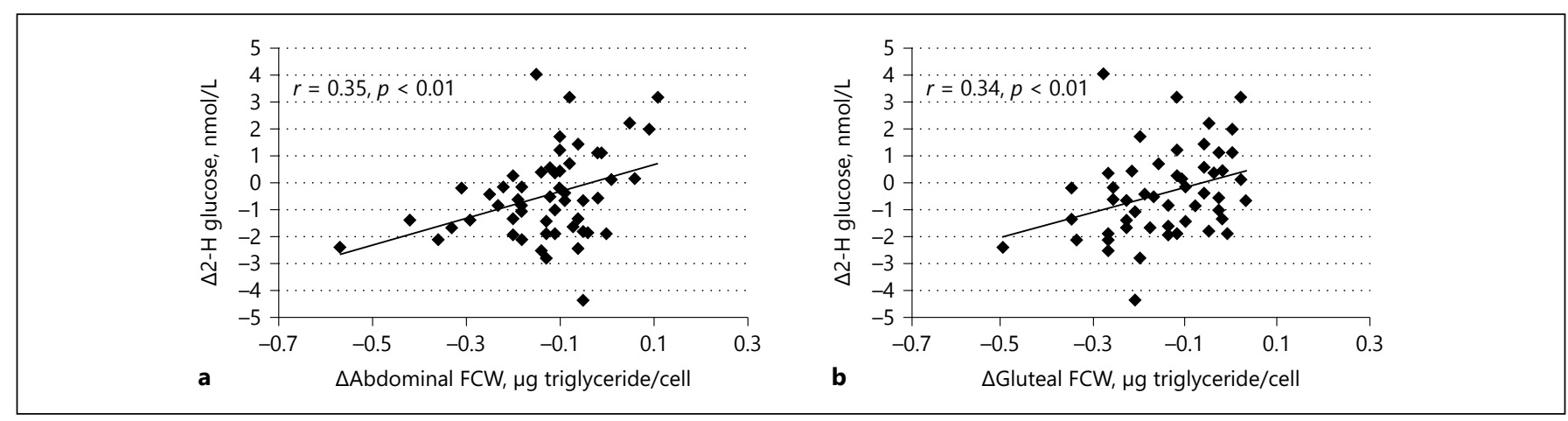

Fig. 3. Relationship of changes in abdominal (a) and gluteal (b) FCW to changes in 2-h glucose in all participants (WL and AEX + WL combined). 
dominal region, despite evidence that $\mathrm{ABD}$ FCW and visceral fat area seem to be stronger predictors of glucose intolerance and insulin resistance then GLT FCW $[6,28]$ and subcutaneous fat area [29] respectively. We find that reductions in FCW appear to depend upon the intervention and glucose-tolerance status, as women with baseline glucose intolerance undergoing WL have the greatest reductions in FCW, suggesting a link between fat cell metabolism and insulin resistance. Thus, in overweight and obese, older women, interventions that lead to the greatest reductions in FCW and abdominal fat area seem to have the greatest impact on glucose metabolism. These data suggest that women who have the highest accumulation of central body fat have the ability to make the greatest glucose metabolic improvements and that it is the overall loss of fat and not necessarily that from a particular region that affects improvements in glucose metabolism.

Our results show that in overweight and obese postmenopausal women, the gynoid region contains $\sim 2 \times$ more fat than the android region $(\sim 7.5 \mathrm{vs} . \sim 3.5 \mathrm{~kg})$. The android region makes up only 7-9\% of total body fat and contains $<50 \%$ of its fat in the visceral region. These data, in addition to our finding that upper body fat is a stronger predictor of baseline glucose metabolic dysfunction (HOMA-IR and 2-h glucose) than lower body fat, indicate the robust influence of central obesity on metabolic dysfunction and suggest that declines in upper body fat may have greater benefit to glucose metabolism than lower body fat. To the best of our knowledge, this is the only study examining the change in the ratio of android to gynoid fat mass by DXA following WL. Previous studies show that WHR does not change following WL in women, even when metabolic improvements (i.e., increases in $\mathrm{VO}_{2} \mathrm{max}$ and reductions in fasting lipid and glucose profiles) are observed $[13,30]$. However, other studies show declines in WHR following WL [31-33] and WL combined with exercise $[34,35]$. We show that women participating in AEX + WL reduce their abdominal to gluteal fat mass ratio and that this change is greater than in women undergoing WL alone; however, the change in the ratio of android to gynoid fat mass did not correlate with the improvements in glucose metabolism. Thus, it appears that although the ratio of android to gynoid fat mass is reduced with the addition of aerobic exercise to $\mathrm{WL}$, it is not the mechanism for improvements in glucose tolerance.

While many studies examine how changes in visceral and subcutaneous abdominal fat relate to metabolic improvements following WL and AEX + WL [36-38], surprisingly a few examine this relationship utilizing the change in the ratio, with mixed outcomes observed [39-41]. It appears that the loss of fat from each depot may be influenced by gender [42] and the amount of weight lost [36]. A systematic review reports that visceral fat may be providing energy at times of acute negative energy balance [36]; therefore, our gradual WL may not have been sufficient stimuli to require the breakdown of visceral fat for energy utilization beyond that required from subcutaneous tissue. Also, this review did not find an overall effect of exercise with and without WL on the ratio of visceral to subcutaneous abdominal fat (when expressed as \% change) [36], suggesting that WL is of greater influence than exercise.

The results of the few studies that examine the effects of WL with and without exercise on the ratio of abdominal to gluteal FCW are equivocal. In women, WL alone seems to either decrease [43] or increase [13] the ratio of abdominal to gluteal FCW, whereas our findings and those of You et al. [13] show that the addition of AEX to WL is associated with no change in the ratio. We suspect that this heterogeneity is due to differences in subject characteristics and interventions, which include menopausal status, presence of central obesity, WL achieved, and differences in exercise intensities. Paracrine responses to WL may affect regional lipid accumulation, including those regulating triglyceride accumulation (i.e., lipoprotein lipase activity) and lipolysis (i.e., hormone sensitive lipase) [44]. This may further be modulated by exercise, as it appears that endurance-trained women have preferential lipid mobilization from subcutaneous abdominal compared to femoral adipose tissue stores [45]. Unfortunately, this study was limited to subcutaneous FCW assessment, but it is suggested that visceral adipocytes may be more sensitive to weight reduction because visceral adipocytes appear more metabolically active and sensitive to lipolysis than subcutaneous adipocytes [46]. A more comprehensive molecular examination of the effects of WL and exercise on adipocyte metabolism would help clarify these issues.

In summary, these results suggest that it is reductions in abdominal fat area and subcutaneous FCW, but not the ratios of visceral to subcutaneous fat areas or upper to lower body fat, that have the greatest influence on glucose metabolism. Future studies should focus on the mechanisms by which WL with and without exercise training impact fat cell lipid storage capacity to improve glucose metabolism in postmenopausal women. 


\section{Acknowledgments}

Our appreciation is extended to the women who participated in this study. We are grateful to the medical team, exercise physiologists, and RDs of the University of Maryland Division of Gerontology and Geriatric Medicine and Baltimore Veterans Affairs Geriatric Research, Education and Clinical Center (GRECC) for their assistance to this project. This work was funded by the Department of Veterans Affairs Career Development Award Number IK2 RX-000944 (M.C.S.) and IK2 RX-001788-01 (O.R.A.) and Senior Research Career Scientist (A.S.R.) from the United States Department of Veterans Affairs Rehabilitation R\&D (Rehab
RD) Service, the National Institute on Aging grants R01-AG19310 (A.S.R.), R01-AG20116 (A.P.G.), Claude D. Pepper Older Americans Independence Center P30-AG028747, NIDDK MidAtlantic Nutrition Obesity Research Center (NIH P30 DK072488), GCRC of the University of Maryland, Baltimore (5M01RR016500), and Baltimore VA GRECC and Research Service.

\section{Disclosure Statement}

All authors have no conflicts of interest to disclose.

\section{References}

1 Shuster A, Patlas M, Pinthus JH, Mourtzakis $\mathrm{M}$ : The clinical importance of visceral adiposity: a critical review of methods for visceral adipose tissue analysis. Br J Radiol 2012;85: $1-10$.

2 Sekikawa A, Eguchi H, Igarashi K, Tominaga M, Abe T, Fukuyama H, Kato T: Waist to hip ratio, body mass index, and glucose intolerance from Funagata population-based diabetes survey in Japan. Tohoku J Exp Med 1999; 189:11-20.

3 Krotkiewski M, Bjorntorp P, Sjostrom L, Smith U: Impact of obesity on metabolism in men and women. Importance of regional adipose tissue distribution. J Clin Invest 1983;72: 1150-1162.

4 Weyer C, Foley JE, Bogardus C, Tataranni PA, Pratley RE: Enlarged subcutaneous abdominal adipocyte size, but not obesity itself, predicts type II diabetes independent of insulin resistance. Diabetologia 2000;43:1498-1506.

5 Ryan AS: Insulin resistance with aging: effects of diet and exercise. Sports Med 2000;30:327346.

6 Goodpaster BH, Thaete FL, Simoneau JA, Kelley DE: Subcutaneous abdominal fat and thigh muscle composition predict insulin sensitivity independently of visceral fat. Diabetes 1997;46:1579-1585.

7 Davis SR, Castelo-Branco C, Chedraui P, Lumsden MA, Nappi RE, Shah D, Villaseca P; Writing Group of the International Menopause Society for World Menopause Day: Understanding weight gain at menopause. Climacteric 2012;15:419-429.

8 Gurr MI, Jung RT, Robinson MP, James WP: Adipose tissue cellularity in man: the relationship between fat cell size and number, the mass and distribution of body fat and the history of weight gain and loss. Int J Obes 1982; 6:419-436.

9 Lofgren P, Andersson I, Adolfsson B, Leijonhufvud BM, Hertel K, Hoffstedt J, Arner P: Long-term prospective and controlled studies demonstrate adipose tissue hypercellularity and relative leptin deficiency in the postobese state. J Clin Endocrinol Metab 2005;90:62076213.

WL, Exercise, and Body Fat Distribution
10 Singh P, Somers VK, Romero-Corral A, SertKuniyoshi FH, Pusalavidyasagar S, Davison DE, Jensen MD: Effects of weight gain and weight loss on regional fat distribution. Am J Clin Nutr 2012;96:229-233.

11 Andersson DP, Eriksson Hogling D, Thorell A, Toft E, Qvisth V, Naslund E, Thorne A, Wiren M, Lofgren P, Hoffstedt J, Dahlman I, Mejhert N, Ryden M, Arner E, Arner P: Changes in subcutaneous fat cell volume and insulin sensitivity after weight loss. Diabetes Care 2014;37:1831-1836.

12 Ryan AS, Ortmeyer HK, Sorkin JD: Exercise with calorie restriction improves insulin sensitivity and glycogen synthase activity in obese postmenopausal women with impaired glucose tolerance. Am J Physiol Endocrinol Metab 2012;302:E145-E152.

13 You T, Murphy KM, Lyles MF, Demons JL, Lenchik L, Nicklas BJ: Addition of aerobic exercise to dietary weight loss preferentially reduces abdominal adipocyte size. Int J Obes (Lond) 2006;30:1211-1216.

14 Nicklas BJ, Wang X, You T, Lyles MF, Demons J, Easter L, Berry MJ, Lenchik L, Carr JJ: Effect of exercise intensity on abdominal fat loss during calorie restriction in overweight and obese postmenopausal women: a randomized, controlled trial. Am J Clin Nutr 2009;89:1043-1052.

15 Rossi AP, Fantin F, Zamboni GA, Mazzali G, Zoico E, Bambace C, Antonioli A, Pozzi Mucelli R, Zamboni M: Effect of moderate weight loss on hepatic, pancreatic and visceral lipids in obese subjects. Nutr Diabetes 2012;2:e32.

16 Lesser IA, Dick TJ, Guenette JA, Hoogbruin A, Mackey DC, Singer J, Lear SA: The association between cardiorespiratory fitness and abdominal adiposity in postmenopausal, physically inactive South Asian women. Prev Med Rep 2015;2:783-787.

17 Kim MJ, Maachi M, Debard C, Loizon E, Clement K, Bruckert E, Hainque B, Capeau J, Vidal H, Bastard JP: Increased adiponectin receptor-1 expression in adipose tissue of impaired glucose-tolerant obese subjects during weight loss. Eur J Endocrinol 2006;155:161165.
18 Steven S, Hollingsworth KG, Small PK, Woodcock SA, Pucci A, Aribisala B, Al-Mrabeh A, Daly AK, Batterham RL, Taylor R: Weight loss decreases excess pancreatic triacylglycerol specifically in type 2 diabetes. Diabetes Care 2016;39:158-165.

19 Jenkins NT, Hagberg JM: Aerobic training effects on glucose tolerance in prediabetic and normoglycemic humans. Med Sci Sports Exerc 2011;43:2231-2240.

20 Malin SK, Kirwan JP: Fasting hyperglycaemia blunts the reversal of impaired glucose tolerance after exercise training in obese older adults. Diabetes Obes Metab 2012;14:835841.

21 Dietary guidelines for healthy American adults. A statement for physicians and health professionals by the Nutrition Committee, American Heart Association. Circulation 1988;77:721A-724A.

22 National Health and Nutrition Examination Survey. Dual Energy X-Ray Absorp tiometry - Android/Gynoid Measurements. 2013 03/10/2015. http://wwwn.cdc.gov/nchs/ nhanes/2005-2006/DXXAG_D.htm.

23 Kerner W, Bruckel J: Definition, classification and diagnosis of diabetes mellitus. Exp Clin Endocrinol Diabetes 2014;122:384-386.

24 Purves RD: Optimum numerical integration methods for estimation of area-under-thecurve (AUC) and area-under-the-momentcurve (AUMC). J Pharmacokinet Biopharm 1992;20:211-226.

25 Matthews DR, Hosker JP, Rudenski AS, Naylor BA, Treacher DF, Turner RC: Homeostasis model assessment: insulin resistance and beta-cell function from fasting plasma glucose and insulin concentrations in man. Diabetologia 1985;28:412-419.

26 Lavau M, Susini C, Knittle J, Blanchet-Hirst $S$, Greenwood MR: A reliable photomicrographic method to determining fat cell size and number: application to dietary obesity. Proc Soc Exp Biol Med 1977;156:251256.

27 Hirsch J, Gallian E: Methods for the determination of adipose cell size in man and animals. J Lipid Res 1968;9:110-119. 
28 Lundgren M, Svensson M, Lindmark S, Renstrom F, Ruge T, Eriksson JW: Fat cell enlargement is an independent marker of insulin resistance and 'hyperleptinaemia'. Diabetologia 2007;50:625-633.

29 Usui C, Asaka M, Kawano H, Aoyama T, Ishijima T, Sakamoto S, Higuchi M: Visceral fat is a strong predictor of insulin resistance regardless of cardiorespiratory fitness in nondiabetic people. J Nutr Sci Vitaminol (Tokyo) 2010;56:109-116.

30 Wing RR, Jeffery RW, Burton LR, Thorson C, Kuller LH, Folsom AR: Change in waist-hip ratio with weight loss and its association with change in cardiovascular risk factors. Am J Clin Nutr 1992;55:1086-1092.

31 Pasquali R, Antenucci D, Casimirri F, Venturoli S, Paradisi R, Fabbri R, Balestra V, Melchionda N, Barbara L: Clinical and hormonal characteristics of obese amenorrheic hyperandrogenic women before and after weight loss. J Clin Endocrinol Metab 1989;68:173-179.

32 Hainer V, Stich V, Kunesova M, Parizkova J, Zak A, Wernischova V, Hrabak P: Effect of 4 -wk treatment of obesity by very-low-calorie diet on anthropometric, metabolic, and hormonal indexes. Am J Clin Nutr 1992;56(1 suppl):281S-282S.

33 Park HS, Lee KU: Postmenopausal women lose less visceral adipose tissue during a weight reduction program. Menopause 2003; 10:222-227.

34 Maiorana A, O’Driscoll G, Goodman C, Taylor R, Green D: Combined aerobic and resis- tance exercise improves glycemic control and fitness in type 2 diabetes. Diabetes Res Clin Pract 2002;56:115-123.

35 Nalini M, Moradi B, Esmaeilzadeh M, Maleki M: Does the effect of supervised cardiac rehabilitation programs on body fat distribution remained long time? J Cardiovasc Thorac Res 2013;5:133-138.

36 Chaston TB, Dixon JB: Factors associated with percent change in visceral versus subcutaneous abdominal fat during weight loss: findings from a systematic review. Int J Obes (Lond) 2008;32:619-628.

37 Busetto L: Visceral obesity and the metabolic syndrome: effects of weight loss. Nutr Metab Cardiovasc Dis 2001;11:195-204.

38 Ohkawara K, Tanaka S, Miyachi M, IshikawaTakata K, Tabata I: A dose-response relation between aerobic exercise and visceral fat reduction: systematic review of clinical trials. Int J Obes (Lond) 2007;31:1786-1797.

39 Kanai H, Tokunaga K, Fujioka S, Yamashita S, Kameda-Takemura KK, Matsuzawa Y: Decrease in intra-abdominal visceral fat may reduce blood pressure in obese hypertensive women. Hypertension 1996;27:125129.

40 Fujioka S, Matsuzawa Y, Tokunaga K, Kawamoto T, Kobatake T, Keno Y, Kotani K, Yoshida S, Tarui S: Improvement of glucose and lipid metabolism associated with selective reduction of intra-abdominal visceral fat in premenopausal women with visceral fat obesity. Int J Obes 1991;15:853-859.
41 Park HS, Lee K: Greater beneficial effects of visceral fat reduction compared with subcutaneous fat reduction on parameters of the metabolic syndrome: a study of weight reduction programmes in subjects with visceral and subcutaneous obesity. Diabet Med 2005;22: 266-272.

42 Gallagher D, Heshka S, Kelley DE, Thornton J, Boxt L, Pi-Sunyer FX, Patricio J, Mancino J, Clark JM; MRI Ancillary Study Group of Look AHEAD Research Group: Changes in adipose tissue depots and metabolic markers following a 1-year diet and exercise intervention in overweight and obese patients with type 2 diabetes. Diabetes Care 2014;37:33253332.

43 Presta E, Leibel RL, Hirsch J: Regional changes in adrenergic receptor status during hypocaloric intake do not predict changes in adipocyte size or body shape. Metabolism 1990; 39:307-315.

44 Berman DM, Nicklas BJ, Ryan AS, Rogus EM, Dennis KE, Goldberg AP: Regulation of lipolysis and lipoprotein lipase after weight loss in obese, postmenopausal women. Obes Res 2004;12:32-39.

45 Mauriege P, Prud'Homme D, Marcotte M, Yoshioka M, Tremblay A, Despres JP: Regional differences in adipose tissue metabolism between sedentary and endurance-trained women. Am J Physiol 1997;273(3 pt 1):E497-E506.

46 Bjorntorp P: Regional obesity; in Bjorntorp P, Brodoff BN (eds): Obesity. Philadelphia, JB Lippincott, 1992, pp 579-586. 